\title{
EVALUASI SISTEM INSTALASI LISTRIK PADA KANTOR DPRD KOTA PALOPO
}

\section{EVALUATION OF ELECTRICAL INSTALLATION SYSTEM AT PALOPO CITY DPRD OFFICE}

\author{
Rahmad Hidayat Dongka \\ Universitas Nani Bili Nusantara \\ rahmatdongka@gmail.com
}

\begin{abstract}
Abstrak
Penelitian ini merupakan penelitian deskriptif yang bertujuan untuk memberikan gambaran tentang sistem instalasi listrik yang berpatokan pada standar nilai sesuai dengan PUIL 2000. Populasi dalam penelitian ini adalah seluruh gedung, penghantar, pengaman, dan pembumian instalasi. Sedangkan sampelnya adalah penghantar, pengaman, dan pembumian pada panel utama. Metode yang digunakan dalam pengumpulan data adalah observasi, wawancara, dan dokumentasi.

Hasil penelitian menunjukkan bahwa Kemampuan hantar arus dan pembumian sistem instalasi listrik sesuai standar PUIL 2000. Sedangkan pengaman yang terpasang hendaknya ditinjau ulang karena kapasitas pengaman terlalu besar hal ini akan berakibat pada instalasi tersebut, dapat merusak penampang kabel instalasi listrik yaitu penampang kabel akan mengalami kehilangan tahanan isolasi, dan pengaman akan lambat untuk memutuskan arus, sehingga bisa mengakibatkan kebakaran apabila terjadi beban lebih atau hubunng singkat. Tidak adanya pengaman sirkit akhir pada setiap ruangan dan hanya menyambung pada sirkit cabang.
\end{abstract}

Kata kunci: Sistem Instalasi Listrik, Kantor, PUIL 2000

\begin{abstract}
This research is a descriptive study which aims to provide an overview of the electrical installation system based on the standard value according to PUIL 2000. The population in this study are all buildings, conduits, safeguards, and installation grounding. While the sample is conductor, safety, and earthing on the main panel. The methods used in data collection are observation, interviews, and documentation. The results show that the current conductivity and grounding of the electrical installation system is in accordance with the standards of PUIL 2000. While the installed safety should be reviewed because the safety capacity is too large this will result in the installation, it can damage the cross section of the electrical installation cable, namely the cable cross section will experience loss of resistance. insulation, and the safety will be slow to cut the current, so that it can cause a fire if there is an overload or a short relationship. There is no final safety circuit in each room and only connects to branch circuit.
\end{abstract}

Keywords: Electrical Installation Systems, Office, PUIL 2000 


\section{PENDAHULUAN}

Sistem perancangan, pemasangan, pengoperasian, dan pemeliharaan instalasi listrik, harus memenuhi beberapa prinsip dasar [1] keamanan, kehandalan, mutu terjamin, ketercapaian, keindahan, ekonomis, dan mudah diperluas. Agar listrik dapat digunakan dengan seaman mungkin sesuai dengan maksud dan tujuan PUIL, yaitu pengusahaan instalasi listrik terselenggara dengan baik, untuk menjamin keselamatan manusia terhadap bahaya kejut listrik, keamanan instalasi listrik beserta kelengkapannya, keamanan gedung beserta isinya dari kebakaran akibat listrik, dengan adanya prinsip dasar instalasi listrik tersebut diharapkan dapat mendukung terciptanya kualitas pemasangan instalasi listrik yang baik.

Ditinjau dari daerah pelayanan beban di Tana Luwu khususnya di Kota Palopo sebagai Kota Madya, maka Kantor DPRD Kota Palopo termasuk salah satu pengguna energi listrik yang besar untuk kegiatan operasionalnya. Sistem penyediaan tenaga listrik Kantor DPRD Kota Palopo menggunakan suplay PLN Ranting Palopo dengan daya terpasang 41.500 VA, yang dipergunakan pada ruangan operasional peralatan komputer, lampu, AC (air conditioner) dan lain sebagainya. Berbagai upaya pihak manajemen kantor dalam mewujudkan peningkatan mutu, antara lain melakukan penambahan peralatan, merenovasi dan pendirian bangunan-bangunan yang baru dalam rangka standarisasi mutu suatu kantor. Hampir seluruh sistem atau jaringan instalasi listrik kantor, utamanya pada gedung-gedung yang diberi penambahan beban tanpa memperhatikan penampang penghantar, pengaman, dan pembumian yang digunakan. Oleh karena itu Kantor DPRD Kota Palopo perlu di evaluasi untuk mengetahui apakah instalasi tersebut memenuhi standar instalasi listrik yang berlaku dalam hal ini Persyaratan Umum Instalasi Listrik 2000.[2]

Tujuan penelitian yang ingin dicapai, yaitu untuk mengevaluasi sistem instalasi listrik Kantor DPRD Kota Palopo berdasarkan PUIL 2000. Identifikasi masalah dalam penelitian ini meliputi : kemampuan penghantar instalasi listrik dari panel induk ke panel cabang, pengaman yang digunakan dan pembumian, sedangkan metode penelitian yang digunakan adalah Penelitian ini merupakan penelitian deskriptif yang bertujuan memberikan penjelasan atau gambaran tentang keadaan sistem instalasi listrik yang berpatokan pada standar nilai sesuai dengan PUIL 2000.

\section{DASAR TEORI DAN METODOLOGI}

\subsection{Dasar Teori}

Evaluasi merupakan salah satu komponen dalam manajemen pengawasan yang berarti kegiatan untuk mengadakan perbandingan antara hasil yang sesungguhnya dan standar yang ditetapkan, sekaligus menetapkan perbedaan-perbedaan seandainya terjadi kelainan-kelainan atau deviasi.[4]

Instalasi listrik ialah jaringan perlengkapan yang mengatur dan membangkit tenaga listrik. Instalasi listrik ialah instalasi untuk membangkitkan, distribusi, pelayanan dan pemakaian tenaga listrik.[2] Pemasangan instalasi listrik harus memenuhi ketentuan PUIL 2000, sehingga instalasi tersebut aman untuk digunakan sesuai dengan maksud dan tujuan penggunaannya, mudah dioperasikan dan dipelihara. Kemapuan penghantar untuk mengalirkan nilai arus secara terus menerus pada kondisi tertentu, tanpa menimbulkan suhu tetap yang melebihi harga tertentu. Pada umumnya KHA dari penghantar yang digunakan dalam setiap sirkuit cabang tidak boleh diturunkan di bawah nilai pengenal gawai proteksi. [2] 
Pengaman ialah suatu peralatan listrik yang menentukan kelangsungan penyaluran daya listrik ke konsumen, karena dapat mengamankan suatu sistem rangkaian listrik apabila terjadi suatu gangguan yang tidak diinginkan tanpa merusak peralatan instalasi tersebut [3]

Sistem pembumian juga dapat didefinisikan sebagai suatu usaha untuk mengadakan hubungan sistem dengan tanah (bumi) menggunakan penghantar dan elektroda tanah. Sistem ini juga sebagai penyaluran arus bocor yang dimaksud ialah adanya arus/tegangan pada bagian listrik yang pada keadaan normal bagian tersebut tidak bertegangan. dengan adanya sistem pembumian dalam rangkaian ini maka apabila terjadi arus bocor orang yang menyentuh benda/mesin-mesin listrik tersebut tidak akan terkena kejutan listrik dan sebagai pelindung terhadap mesin-mesin listrik.[5]

\subsection{Metodologi}

Penelitian ini berfokus untuk mengevaluasi kemampuan hantar yaitu, kemampuan penghantar untuk mengalirkan arus secara terus menerus pada kondisi tertentu, kapasitas pengaman yaitu, besarnya kapasitas pengaman yang digunakan dengan arus dan daya yang mengalir, dan sistem pembumian yang digunakan pada instalasi listrik tersebut.

Standarisasi diperlukan sebagai pedoman dalam perancangan, pemasangan, pengoperasian, dan pemeliharaan instalasi listrik. Jika seluruh standar telah dipenuhi, diharapkan instalasi listrik dapat berfungsi dengan baik sesuai dengan maksud penggunaanya, menjamin keselamatan menusia, gedung beserta isinya dari bahaya yang mungkin timbul akibat pemanfaatan listrik. Kerangka pikir penelitian ini selanjutnya digambarkan pada bagan berikut ini

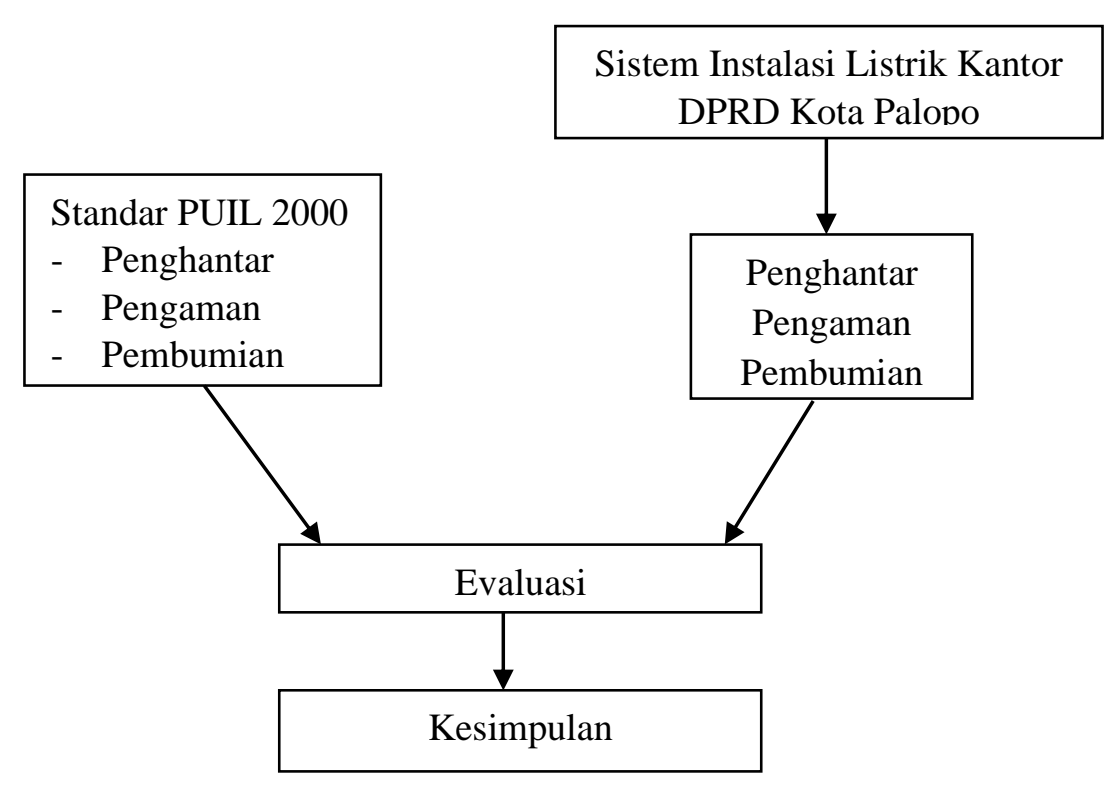

Gambar 1. Kerangka Pikir

\section{HASIL PENELITIAN DAN PEMBAHASAN}

\subsection{Deskripsi Hasil Penelitian}

Pengambilan data yang telah dilakukan, maka hasil dari pengambilan data yang dianalisis seperti pada tabel 1 dibawah ini : 
JEC VOL. 6 NO. 2

Jurnal Electro Luceat [November] [2020]

Tabel 1. Data Ruangan, Jenis Beban Penerangan dan Jenis Beban Tenaga

\begin{tabular}{|c|c|c|c|c|c|c|c|c|}
\hline \multirow{2}{*}{ No } & \multirow{2}{*}{ NAMA RUANGAN } & \multirow{2}{*}{ BEBAN PENERANGAN } & \multicolumn{6}{|c|}{ BEBAN TENAGA } \\
\hline & & & $A C$ & KULKAS & TELEVISI & KOMPUTER & KIPAS ANGIN & POMPA AIR \\
\hline 1 & RuangKetua & TL $20 \mathrm{~W}$ & 1 PK 840 W & $80 \mathrm{~W}$ & $86 \mathrm{~W}$ & - & - & - \\
\hline 3 & Ruang Wakil Ketua II & TL $20 \mathrm{~W}$ & 1 PK $840 \mathrm{~W}$ & $80 \mathrm{~W}$ & - & - & - & - \\
\hline 4 & Ruang Sekwan & TL $20 \mathrm{~W}$ & $1 \mathrm{PK} 840 \mathrm{~W}$ & - & $86 \mathrm{~W}$ & - & - & - \\
\hline 6 & RuangBagian Umum II & TL $20 \mathrm{~W}$ & $1 \mathrm{PK} 840 \mathrm{~W}$ & - & - & - & - & - \\
\hline 7 & RuangBagian Keuangan & TL $20 \mathrm{~W}$ & 1 PK $840 \mathrm{~W}$ & - & - & $150 \mathrm{~W}$ & - & - \\
\hline 8 & Ruang Fraksi 1 & TL $20 \mathrm{~W}$ & 1 PK $840 \mathrm{~W}$ & - & - & - & - & - \\
\hline 9 & RuangFraksi II & TL $20 \mathrm{~W}$ & $1 \mathrm{PK} 840 \mathrm{~W}$ & - & - & - & - & - \\
\hline 10 & RuangKomisiI & TL $20 \mathrm{~W}$ & $1 \mathrm{PK} 840 \mathrm{~W}$ & - & - & - & - & - \\
\hline 14 & Ruang Perundang-undangan & $\mathrm{TL} 40 \mathrm{~W}$ & 1 PK $840 \mathrm{~W}$ & - & - & - & - & - \\
\hline 15 & RuangMusyawarah & $\mathrm{TL} 40 \mathrm{~W}$ & 2 PK $1780 \mathrm{~W}$ & - & - & - & - & - \\
\hline 16 & RuangParipurna & TL $20 \mathrm{~W}$ & 2 PK $1780 \mathrm{~W}$ & - & - & - & - & - \\
\hline 17 & Gedung Aspirasi & TL $20 \mathrm{~W}$ & 1 PK $840 \mathrm{~W}$ & - & - & - & $50 \mathrm{~W}$ & - \\
\hline 18 & RuangPersidangan & TL $20 \mathrm{~W}$ & $1 \mathrm{PK} 840 \mathrm{~W}$ & - & - & - & - & - \\
\hline 19 & RuangPanel Utama & TL $20 \mathrm{~W}$ & $1 \mathrm{PK} 840 \mathrm{~W}$ & - & - & - & - & - \\
\hline 20 & Loby & TL $20 \mathrm{~W}$ & - & - & $86 \mathrm{~W}$ & - & - & - \\
\hline 21 & Toilet & $\mathrm{TL} 20 \mathrm{~W}$ & - & - & - & - & - & $250 \mathrm{~W}$ \\
\hline
\end{tabular}

Tabel 2. Data jenis dan Luas Penampang Kabel

\begin{tabular}{|c|l|c|l|}
\hline No & \multicolumn{1}{|c|}{ Jenis Kabel } & Luas Penampang & \multicolumn{1}{|c|}{ Keterangan } \\
\hline 1 & Penghantar Kawat Arde (insuno) & $10 \mathrm{~mm}^{2}$ & Kabel Pembumian \\
\hline 2 & NYA & $2,5 \mathrm{~mm}^{2}$ & Instalasi Penerangan \\
\hline 3 & NYA & $2,5 \mathrm{~mm}^{2}$ & Instalasi Tenaga \\
\hline 4 & NYY & $4 \times 2,5 \mathrm{~mm}^{2}$ & Instalasi Sirkit Cabang \\
\hline 5 & NYY & $4 \times 50 \mathrm{~mm}^{2}$ & Instalasi Sirkit Utama \\
\hline
\end{tabular}

Tabel 3. Data dan Kapasitas Jenis Pengaman

\begin{tabular}{|c|l|c|l|}
\hline NO & Jenis Pengaman & Kapasitas (A) & \multicolumn{1}{|c|}{ Keterangan } \\
\hline 1 & NFB & 300 & Pengaman Sirkit Utama \\
\hline 2 & NFB & 150 & Pengaman Sirkit Cabang I \\
\hline 3 & NFB & 100 & Pengaman Sirkit Cabang II \\
\hline 4 & NFB & 75 & Pengaman Sirkit Cabang III \\
\hline 5 & MCB & 50 & Pengaman Tiap Fasa R \\
\hline 6 & MCB & 35 & Pengaman Tiap Fasa S \\
\hline 7 & MCB & 25 & Pengaman Tiap Fasa T \\
\hline
\end{tabular}




\subsection{PEMBAHASAN}

Pengolahan data yang digunakan untuk menganalisis sistem instalasi listrik Kantor DPRD Kota Palopo yaitu menggunakan analisis desktiptif dengan melakukan perhitungan-perhitungan sesuai dengan rumus atau persamaan yang relevan. Hasil perhitungan kuat hantar arus, pengaman beban dan pembumian yang seharusnya terpasang pada Instalasi Kantor DPRD Kota Palopo adalah sebagai berikut :

Tabel 4. Data kondisi peralatan instalasi listrik setiap Ruangan

\begin{tabular}{|c|c|c|c|c|c|}
\hline \multirow{2}{*}{$\stackrel{N}{N}$} & \multirow[t]{2}{*}{ NAMA RUANGAN } & \multicolumn{4}{|c|}{ KONDISI PERALATAN } \\
\hline & & Saklar & KKB & KKK & Fitting \\
\hline 1 & Ruang Ketua & Sesuai & Sesuai & Sesuai & Sesuai \\
\hline 2 & Ruang Wakil Ketua I & Sesuai & Sesuai & Sesuai & Sesuai \\
\hline 3 & Ruang Wakil Ketua II & Sesuai & Sesuai & Sesuai & Sesuai \\
\hline 4 & Ruang Sekwan & Sesuai & Sesuai & Sesuai & Sesuai \\
\hline 5 & Ruang Bagian Umum I & Sesuai & Sesuai & Sesuai & Sesuai \\
\hline 6 & Ruang Bagian Umum II & Sesuai & Sesuai & Sesuai & Sesuai \\
\hline 7 & Ruang Bagian Keuangan & Sesuai & Sesuai & Sesuai & Sesuai \\
\hline 8 & Ruang Fraksi 1 & Sesuai & Sesuai & Sesuai & Sesuai \\
\hline 9 & Ruang Fraksi II & Sesuai & Sesuai & Sesuai & Sesuai \\
\hline 10 & Ruang Komisi I & Sesuai & Sesuai & Sesuai & Sesuai \\
\hline 11 & Ruang Komisi II & Sesuai & Sesuai & Sesuai & Sesuai \\
\hline 12 & Ruang Komisi III & Sesuai & Sesuai & Sesuai & Sesuai \\
\hline 13 & Ruang Kehormatan & Sesuai & Sesuai & Tidak Sesuai & Sesuai \\
\hline 14 & Ruang Perundang-undangan & Sesuai & Sesuai & Sesuai & Sesuai \\
\hline 15 & Ruang Musyawarah & Sesuai & Sesuai & Tidak Sesuai & Sesuai \\
\hline 16 & Ruang Paripuma & Tidak Sesuai & Sesuai & Tidak Sesuai & Tidak Sesuai \\
\hline 17 & Gedung Aspirasi & Sesuai & Sesuai & Sesuai & Sesuai \\
\hline 18 & Ruang Persidangan & Tidak Sesuai & Sesuai & Tidak Sesuai & Tidak Sesuai \\
\hline 19 & Ruang Panel Utama & Sesuai & Sesuai & - & Sesuai \\
\hline 20 & Loby & Tidak Sesuai & - & Sesuai & Tidak Sesuai \\
\hline 21 & Toilet & Tidak Sesuai & Tidak Sesuai & - & Tidak Sesuai \\
\hline
\end{tabular}

Tabel 5. Evaluasi Kondisi, jumlah dan persentase Saklar setiap ruangan

\begin{tabular}{|c|c|c|c|}
\hline No & Kondisi Saklar & jumlah & Persentase (\%) \\
\hline 1. & Sesuai & 17 & 80,95 \\
\hline 2. & Tidak Sesuai & 4 & 19,05 \\
\hline
\end{tabular}

PUIL 2000 dijelaskan bahwa saklar harus dipasang sehinngga: Bagian yang dapat bergerak, tidak bertegangan pada waktu saklar dalam keadaan terbuka atau tidak menghubung. Kedudukan kontak semua tuas saklar dan tombol saklar dalam satu inatalasi harus seragam; misalnya akan menghubung jika tuasnya didorong $\mathrm{ke}$ atas atau tombolnya ditekan (ketentuan 2.5.2.3).

Tabel 6. Evaluasi Kondisi, jumlah dan persentase KKB setiap ruangan

\begin{tabular}{|c|c|c|c|}
\hline No & Kondisi KKB & jumlah & Persentase (\%) \\
\hline 1. & Sesuai & 19 & 97,47 \\
\hline 2. & Tidak Sesuai & 1 & 2,53 \\
\hline
\end{tabular}


JEC VOL. 6 NO. 2

Jurnal Electro Luceat [November] [2020]

Tabel 7. Evaluasi Kondisi, jumlah dan persentase KKK setiap ruangan

\begin{tabular}{|c|c|c|c|}
\hline No & Kondisi KKK & jumlah & Persentase (\%) \\
\hline 1. & Sesuai & 15 & 71,42 \\
\hline 2. & Tidak Sesuai & 4 & 28,58 \\
\hline
\end{tabular}

PUIL 2000 dijelaskan bahwa kotak kontak fase tunggal, baik yang berkutub dua maupun tiga harus dipasang sehingga kutub netralnya ada di sebelah kanan atau di sebelah bawah kutub tegangan (ketentuan 2.5.2.6).

Tabel 8. Evaluasi Kondisi, jumlah dan persentase Fitting setiap ruangan

\begin{tabular}{|c|c|c|c|}
\hline No & Kondisi Fitting & jumlah & Persentase (\%) \\
\hline 1. & Sesuai & 17 & 80,95 \\
\hline 2. & Tidak Sesuai & 4 & 19,05 \\
\hline
\end{tabular}

PUIL 2000 dijelaskan bahwa fitting lampu jenis Edison harus dipasang dengan cara menghubungkan kontak dasarnya pada penghantar fase, dan kontak luarnya pada penghnatar netral (ketentuan 2.5.2.4).

Tabel 9. Data hasil perhitungan luas penampang penghantar sirkit cabang

\begin{tabular}{|c|c|c|c|c|c|}
\hline \multirow{2}{*}{$\begin{array}{c}\text { Sirkit } \\
\text { cabang }\end{array}$} & \multirow{2}{*}{ Panjang Kabel (m) } & \multirow{2}{*}{$\begin{array}{c}\text { Daya } \\
(\mathrm{VA})\end{array}$} & $\begin{array}{c}\text { Luas penampang kabel } \\
\left(\mathrm{mm}^{2}\right)\end{array}$ & \multirow{2}{*}{ Keterangan } \\
\cline { 4 - 5 } & & & Terpasang & $\begin{array}{c}\text { Hasil } \\
\text { Perhitungan }\end{array}$ & \\
\hline I & 10 & 19520 & 2,5 & 1,407 & Sesuai \\
II & 15 & 15080 & 2,5 & 1,82 & Sesuai \\
III & 20 & 5800 & 2,5 & 0,82 & Sesuai \\
\hline
\end{tabular}

Hasil perhitungan penghantar sirkit utama yang terpasang memenuhi syarat dan standar karena luas penampang penghantar yang digunaka yaitu $4 \times 50 \mathrm{~mm}^{2}$ sedangkan hasil perhitungan yaitu $0,359 \mathrm{~mm}^{2}$ atau sesuai yang terpasang.

Tabel 10 Data hasil perhitungan kapasitas pengaman sirkit cabang tiap phasa

\begin{tabular}{|c|c|c|c|c|}
\hline \multirow{2}{*}{$\begin{array}{c}\text { Sirkit cabang } \\
\text { tiap phasa }\end{array}$} & $\begin{array}{c}\text { Daya } \\
\text { (VA) }\end{array}$ & \multicolumn{2}{|c|}{$\begin{array}{c}\text { Kapasitas Pengaman } \\
\text { (A) }\end{array}$} & Keterangan \\
\cline { 3 - 4 } & Terpasang & $\begin{array}{c}\text { Hasil } \\
\text { Perhitungan }\end{array}$ & \\
\hline $\mathrm{R}$ & 6580 & 50 & 40,45 & Sesuai \\
$\mathrm{S}$ & 6560 & 50 & 35,08 & Sesuai \\
$\mathrm{T}$ & 6380 & 50 & 39,32 & Sesuai \\
\hline $\mathrm{R}$ & 5100 & 35 & 31,36 & Sesuai \\
$\mathrm{S}$ & 5880 & 35 & 36,15 & Tidak Sesuai \\
$\mathrm{T}$ & 4100 & 35 & 25,2 & Sesuai \\
\hline
\end{tabular}


JEC VOL. 6 NO. 2

Jurnal Electro Luceat [November] [2020]

\begin{tabular}{|l|l|l|l|l|}
\hline $\mathrm{R}$ & 1920 & 25 & 11,79 & Sesuai \\
$\mathrm{S}$ & 1920 & 25 & 11,79 & Sesuai \\
$\mathrm{T}$ & 1960 & 25 & 12,05 & Sesuai \\
\hline
\end{tabular}

Tabel 11. Data hasil perhitungan kapasitas pengaman sirkit cabang tiap phasa

\begin{tabular}{|c|c|c|c|c|}
\hline \multirow{2}{*}{ Sirkit cabang } & \multirow{2}{*}{$\begin{array}{c}\text { Kapasitas } \\
\text { beban } \\
\text { (VA) }\end{array}$} & \multicolumn{2}{|c|}{ Kapasitas Pengaman } & \multirow{2}{*}{ Keterangan } \\
\cline { 3 - 4 } & Terpasang & $\begin{array}{c}\text { Hasil } \\
\text { Perhitungan }\end{array}$ & \\
\hline I & 19520 & 150 & 40,16 & Tidak Sesuai \\
II & 15080 & 100 & 31,02 & Tidak Sesuai \\
III & 5800 & 75 & 11,92 & Tidak Sesuai \\
\hline
\end{tabular}

Pengaman yang digunakan adalah NFB dan MCB. NFB dengan nilai terpasang 300 Ampere. Dari hasil perhitungan diatas didapat 105,84 Ampere. Sedangkan MCB Pengaman yang digunakan adalah MCB 50 A maka pengaman yang terpasang tidak sesuai dengan hasil perhitungan atau yang seharusnya terpasang.

Tabel 12. Hasil Pengukuran Resistansi Pembumian

\begin{tabular}{|c|c|c|c|c|c|}
\hline \multirow{2}{*}{ NO } & \multirow{2}{*}{ NAMA BANGUNAN } & \multicolumn{4}{|c|}{ HASIL PENGUKURAN } \\
\cline { 3 - 6 } & & 1 & 2 & 3 & RATA-RATA \\
\hline 1 & Kantor DPRD Kota Palopo & 0,5 & 0,5 & 0,52 & 0,52 \\
\hline
\end{tabular}

Hasil pengukuran resistansi pembumian untuk jenis tanah pasir basah berkisar antara $0,5 \Omega$ 0,52 dengan tahanan jenis tanah $\rho=200 \Omega-\mathrm{m}$. Hal ini disebabkan karena resistansi jenis tanah yang sama dan jenis elektroda yang digunakan juga sama sehingga hasil pengukuran di setiap titik pengukuran relatif sama. Resistansi pembumian total seluruh sistem tidak boleh mencapai $10 \Omega$ sehingga baik sebagai pembumian. Sedangkan Hasil perhitungan resistansi pembumian instalasi listrik Kantor DPRD Kota Palopo adalah 2,664 $\Omega$. Nilai resistansi pembumian instalasi listrik Kantor DPRD Kota Palopo berdasarkan hasil pengukuran lebih besar dari hasil perhitungan, hal ini membuktikan bahwa resistansi pembumian instalasi listrik Kantor DPRD Kota Palopo sesuai standar PUIL 2000. Adapun hasil perhitungan besarnya resistansi pembumian untuk jenis tanah pasir basah dengan menggunakan persamaan [6]

$$
\begin{aligned}
\mathrm{R} & =\frac{\rho}{2 \pi \mathrm{L}}\left[\ln \frac{4 \mathrm{~L}}{\alpha}-1\right](\mathrm{Ohm}) \text { sehingga di peroleh sebagai berikut: } \\
R & =\frac{\rho}{2 \pi L}\left[\ln \frac{4 L}{\alpha} 1\right] \\
R & =\frac{200}{2 \times 3,14 \times 70}\left[\ln \frac{4 \times 70}{0,75} 1\right] \\
R & =0,45[5,92]
\end{aligned}
$$




$$
R=2,664 \Omega \text {. }
$$

\section{KESIMPULAN}

a. Kemampuan hantar arus dan penghantar yang terpasang pada setiap sirkit cabang dan utama sesuai standar yang diatur dalam PUIL 2000.

b. Pengaman kabel yang terpasang pada setiap sirkit cabang dan utama hendaknya ditinjau ulang karena kapasitas pengaman terlalu besar hal ini akan berakibat pada instalasi tersebut apabila terjadi beban lebih atau hubung singkat, kemungkinan dapat merusak penampang kabel instalasi listrik yaitu penampang kabel akan mengalami kehilangan tahanan isolasi, kemudian bila terjadi beban lebih atau hubung singkat pengaman akan lambat untuk memutuskan arus, sehingga bisa mengakibatkan kebakaran. Tidak adanya pengaman sirkit akhir pada setiap ruangan dan hanya menyambung pada sirkit cabang tidak sesuai dengan standar PUIL 2000.

c. Sistem pembumian instalasi listrik Kantor DPRD Kota Palopo meliputi jenis pembumian, resistansi pembumian, dan elektroda pembumian yang terpasang. Setelah dievaluasi, maka diperoleh kesimpulan bahwa jenis pembumian, resistansi pembumian, dan elektroda pembumian sesuai dengan standar yang diatur dalam PUIL 2000.

\section{DAFTAR PUSTAKA}

[1] Bakri, Hasrul. 2009. Seri Buku Ajar.Mata Kuliah Instalasi Listrik 1.Disajikan pada perkuliahan semester 3 untuk Program Studi Strata Satu (S1) Pendidikan Teknik Elektro yang diselenggarakan oleh Fakultas Teknik Universitas Negeri Makassar. Makassar: Agustus 2009

[2] Badan Standar Nasional (BSN). 2000. Persyaratan Umum Instalasi Listrik 2000. Jakarta: Yayasan PUIL.

[3] Harten 1995,a. Instalasi Listrik Arus Kuat 1. Bina Cipta. Bandung

[4] Kamaruddin. 1994. Ensiklopedia Manajemen. Jakarta : Bumi Aksara

[5] Sariadi. 1999. Jaringan Distribusi Listrik. Bandung : Angkasa Bandung.

[6] T.S. Hutaruk. 1999, Pengetanahan Netral Sistem Tenaga dan Pengetanahan Peralatan. Jakarta : Erlangga 